ISSN 2447-9071

doi $10.36414 /$ rbmc.v6i14.28
Contato para correspondência: Hermínio Maurício da Rocha Sobrinho

E-mail:

herminio.sobrinho@gmail.com

Conflito de interesse: Não

Financiamento: Recursos próprios

Recebido: 30/12/2019

Aprovado: 30/01/2020

\section{O uso do ácido hialurônico no rejuvenescimento facial}

\section{The use of hyaluronic acid in facial rejuvenation}

Suelen Consoli Braga Vasconcelos' ${ }^{1}$ Flávia Martins Nascente ${ }^{1,2}$ Cláudia Maria Duque de Souza', Hermínio Maurício da Rocha Sobrinho ${ }^{1,3}$

1 Pontifícia Universidade Católica de Goiás - PUC Goiás

${ }^{2}$ Faculdade da Polícia Militar - FPM

${ }^{3}$ Universidade Estadual de Goiás - UEG

\section{Resumo}

Oácido hialurônico $(A H)$ é um dos preenchedores dérmicos temporários mais usados na correção de rítides, linhas esulcos faciais por ser seguroeeficaz. Esteácidoénatural no organismo humanoe dentre as suas funções destaca-se a manutenção do volume, sustentação, hidratação e elasticidade da pele. Múltiplos preenchedores dérmicos estão disponíveis variando em relação às características físicas e químicas, o que influi em seus efeitos. O conhecimento do profissional sobre a anatomofisiologia da pele, assim como as características e propriedades reológicas dos $\mathrm{AH}$, bem como a escolha adequada do produto para a região em que será aplicado e a experiência na aplicação são de suma importância para a obtenção de um resultado natural e duradouro. Os objetivos deste estudo foram apresentar as principais vantagens do uso do AH como preenchedor dérmico, suas indicações, contraindicações, reações adversas epossíveis complicações no tratamento para o rejuvenescimento facial humano. Trata-se deumestudo derevisão bibliográficanarrativa. Foram consultadas as bases de dados virtuais PubMed/ MEDLINE e Portal Periódicos Capes. Estudos demonstraram que a aplicação inadequada do $\mathrm{AH}$ em planos teciduais incorretos é crítico na indução de reações adversas, devido à distensão dos tecidos e ao trauma. Observou-se que reação inflamatória transitória, leve ou moderada e equimoses podem ocorrer alguns dias após o procedimento. Estudos revelam que bons resultados do preenchimento dérmico facial se mantêm por um período variável de 6 a 18 meses. Os procedimentos são rápidos, ambulatoriais, semnecessidades detestes ou afastamentos de atividades diárias, com reações adversas mínimas e complicações raras. Avaliação cuidadosa do paciente, planejamento terapêutico adequado e técnica apurada são fundamentais para alcançar os melhores resultados com o tratamento.

Palavras-Chave: Ácido hialurônico, Preenchimento facial, Reações adversas, Rejuvenescimento cutâneo.

\section{Abstract}

Hyaluronic acid (HA) is one of the most commonly used temporary skin fillers for the correction of ridges, lines and facial furrows as it is safe and effective. This acid is natural in the human body and among its functions it is important to maintain the volume, support, hydration and elasticity of the skin. Multiple dermal fillers are available varying in relation to physical and chemical characteristics, which influences their effects. The knowledge of the professional about the anatomical physiology of the skin, as well as the characteristics and rheological properties of the $A H$, as well as the appropriate choice of the product for the region in which it will be applied and the experience in the application are of paramount importance in order to obtain a natural result and long-lasting. The objective of this study was to highlight the main advantages of $\mathrm{AH}$, its indications, contraindications, adverse reactions and possible complications in the treatment for human facial rejuvenation. This is a study of narrative bibliographic review. The PubMed / MEDLINE and Capes virtual databases were consulted. Studies have shown that the inappropriate application of HA in incorrect tissue plans is critical in inducing adverse reactions, due to the distention of tissues and trauma. Transient, mild or moderate inflammatory reaction and bruising may occur a few days after the procedure. Studies show that good facial 
dermal filling results are maintained for a variable period of 6 to 18 months. The procedures are rapid, outpatient, with no testing requirements or withdrawals from daily activities, with minimal adverse reactions and rare complications. Careful patient assessment, adequate therapeutic planning and accurate technique are essential to achieve the best results with treatment.

Keywords: Hyaluronic acid, Facial filling, Adverse reactions, Skin rejuvenation.

\section{Introdução}

A beleza é um conjunto de características que são agradáveis aos olhos e que são capazes de encantar o observador. O conceito de beleza é variável de acordo com a cultura e opinião pessoal; no entanto, rostos proporcionais, simétricos e bem marcados, parecem ser mais atrativos'.

O envelhecimento é um processo biológico e constante, que é causado por fatores intrínsecos ou extrínsecos. O envelhecimento intrínseco é o processo natural e inevitável com o passar dos anos, o extrínseco acontece precocemente por exposição do organismo a fatores ambientais².

Durante o envelhecimento humano há alterações bioquímicas e estruturais das fibras de colágeno, reduzindo a síntese e aumentando a degradação, como consequência ocorre alteração do volume facial, perda de elasticidade, rítides, sulcos e marcas de expressões ${ }^{3}$.

O preenchimento cutâneo tem a função de amenizar sinais do envelhecimento promovendo rejuvenescimento facial. $\mathrm{O}$ preenchimento ideal deve ser seguro e eficaz, biocompatível, não alergênico, não carcinogênico, reprodutível, estável, de fácil aplicação, tendo um bom custo/benefício e de fácil remoção. Diante desses quesitos o ácido hialurônico (AH) é o que mais se aproxima do ideal4. O AH é utilizado para preenchimento de rugas, cicatrizes, aumento de volume labial, sulco nasojugal e remodelamento do contorno facial ${ }^{5}$.

Algumas reações transitórias relacionadas ao preenchimento dérmico podem ocorrer, como dor, edema, prurido, vermelhidão. As complicações não são frequentes e incluem necrose tecidual, edema persistente, granulomas e cegueira, podendo ser tratadas com injeção local da enzima hialuronidase6. O AH é contraindicado em áreas cutâneas com doenças ativas, lesionadas ou inflamadas?.

Diante da importância e vantagens do uso do $\mathrm{AH}$ no rejuvenescimento facial, o presente trabalho tem por objetivo abordar as suas vantagens, indicações, contraindicações, reações adversas e complicações no tratamento para o rejuvenescimento facial humano.

\section{Métodos}

O presente trabalho constitui uma revisão bibliográfica narrativa, pautando-se na busca de estudos pesquisados em fontes credíveis de informação científica utilizando-se as bases de dados eletrônicas PubMed/MEDLINE (US National Library of Medicine) e Portal Periódicos Capes. Foram pesquisados artigos em língua portuguesa e inglesa publicados no período de 2007 a 2019. Os descritores utilizados na busca foram: Facial Fill, Hyaluronic Acid, Rheology, Skin Aging and Skin Rejuvenation. Durante a pesquisa bibliográfica foram encontrados 87 artigos, deste total, foram selecionados 34 trabalhos que apresentaram texto completo disponível na base de dados virtual, aqueles cujos conteúdos contribuíram para o cumprimento dos objetivos e da relevância deste estudo. Foram excluídos trabalhos duplicados, estudos publicados antes do ano de 2007, bem como aqueles que não apresentavam o texto disponível na íntegra e conteúdos não relacionados aos objetivos deste estudo.

\section{Resultados e Discussão}

O levantamento bibliográfico realizado com o objetivo de apresentar as principais vantagens do uso do ácido hialurônico (AH) como preenchedor dérmico em tratamentos estéticos de rejuvenescimento facial ressalta a sua função de amenizar sinais do envelhecimento cutâneo facial, de forma segura e eficaz, harmonizando rugas, cicatrizes, sulcos, linhas de expressão e no remodelamento do contorno facial ${ }^{4,5}$. Os principais aspectos gerais referentes uso do $\mathrm{AH}$ em procedimentos estéticos de rejuvenescimento facial, suas indicações, contraindicações, possíveis reações adversas e complicações serão abordadas a seguir.

\section{Aspectos Gerais sobre o Ácido Hialurônico}

$\mathrm{O}$ ácido hialurônico $(\mathrm{AH})$ é uma glicosaminoglicano composto de unidades alternadas e repetitivas de ácido D-glicurônico e $\mathrm{N}$-acetil-D-glicosamina com propriedades hidrofílicas, as quais provocam aumento do volume tecidual ${ }^{8}$. Algumas formulações apresentam capacidade de retenção de 
aproximadamente 6 litros de água para cada 1 grama de $\mathrm{AH}$ o que caracteriza a hidratação intensa, tensão e integridade do tecido?.

$\mathrm{O} \mathrm{AH}$ é abundante na matriz extracelular da derme e epiderme, sendo sintetizado principalmente pelos fibroblastos a partir da ação enzima na membrana plasmática (ácido hialurônico sintetase) e pelos queratinócitos da epiderme ${ }^{5}$. A consistência do AH é gelatinosa, possuindo uma alta viscoelasticidade devido a sua característica molecular ${ }^{10}$. O AH imobiliza a água no tecido, alterando o volume dérmico e a viscoelasticidade da matriz extracelular ${ }^{11}$.

O AH sintético foi desenvolvido em 1989 por Endre Balazs, possuindo biocompatibilidade e ausência de imunogenicidade, porém a durabilidade do AH era por volta de apenas 24 horas no tecido cutâneo ${ }^{12}$. O produto injetado de $\mathrm{AH}$ pode apresentar dupla origem: animal, extraído da crista de galo; e não animal (sintética), por um mecanismo de fermentação bacteriana como de cultura de Streptococcus, sendo o mais utilizado nos últimos anos ${ }^{13}$.

$\mathrm{O}$ AH injetado na pele é metabolizado em dióxido de carbono e água e eliminado pelo fígado ${ }^{14}$.

\section{O uso do Ácido Hialurônico em Procedimentos Estéticos}

O AH tem sido utilizado para correção de sulcos, rugas, aumento do volume dos lábios, correção de cicatrizes de acne, reposição do volume supra-auricular, correção nasal, volumização por perda de coxins gordurosos proporcionando uma harmonização facial. Atualmente, o melhor resultado na estética para correção de rítides, perda de contorno e reposição do volume facial é obtido com o $\mathrm{AH}$ reticulado na forma de gel injetável ${ }^{14}$.

O conhecimento detalhado da anatomia facial é importante para minimizar os riscos de injeção intravascular ou intravenosa de $\mathrm{AH}$, assim evitando áreas com grandes vasos sanguíneos com o intuito de prevenir reações inflamatórias, complicações vasculares e formação de nódulos ${ }^{15,16}$.

Para aplicação do AH precisa levar em consideração o volume, a profundidade e a sua viscosidade, em cada tipo de procedimento estético ${ }^{17}$. As principais indicações do seu uso são apresentadas no quadro 1 .

\section{Quadro 1: Indicações do uso do Ácido Hialurônico em Procedimentos Estéticos}

\section{Sulcos nasojugais}

Sulcos nasogenianos

Região periocular

Aumento do volume e contorno labial
Linha de marionete
Região malar
Região mandibular
Região do mento
Região do pescoço
Região das mãos
Cicatrizes
Rinomodelação

Fonte: Bernardes, 20185; Moraes et al. 2017¹0.

\section{Características dos Preenchedores Dérmicos com Ácido Hialurônico}

Existem diversos fabricantes de preenchedores de $\mathrm{AH}$, variando suas características, tais como concentração total de $\mathrm{AH}$, tamanho das partículas, grau de reticulação, a porcentagem de $\mathrm{AH}$ reticulado e a força de extrusão ${ }^{18,19}$.

Os fabricantes reticulam unidades de $\mathrm{AH}$ criando variações entre os produtos, usando 1,4 - butanediol diglicidil éter (BDDE) e divinilsulfona, ambos reagem com os grupos hidroxílicos do $\mathrm{AH}$ fornecendo ligações éter quimicamente estáveis, aumentando o tempo de residência no sítio de inserção e o produto formado, sendo mais resistentes ao calor e a degradação enzimática. A reticulação estabiliza a estrutura através das ligações intermoleculares aumentando a meia vida do $\mathrm{AH}$ e a firmeza do gel. Apenas o $\mathrm{AH}$ reticulado ou $\mathrm{AH}$ insolúvel funciona para o preenchimento dérmico, resistindo a degradação e proporcionando maior longevidade na derme ${ }^{20}$.

Os preenchedores reticulados são classificados em monofásicos ou bifásicos. Os enchimentos monofásicos consistem em um material homogêneo, mistura de AH de alto peso e baixo peso molecular facilitando a sua aplicação, possuindo duas categorias: monodensificados (reticulados uma vez) ou polidensificados (continuamente reticulados). O enchimento bifásico tem partículas heterogêneas e possui uma viscosidade e elasticidade alta $^{20}$.

$\mathrm{O} A \mathrm{H}$ não reticulado, não tem efeito volumizador, possui uma duração mais curta, porém tem a capacidade de difundir nos tecidos periféricos, apropriado para hidratação cutânea ${ }^{21}$.

As diferenças entre os produtos do AH estão na viscosidade, no tamanho das partículas, densidade, capacidade de absorção de água, comportamento reológico, estabilidade à degradação enzimática e a capacidade de estimular a produção de componentes da matriz extracelular, ${ }^{921}$.

A propriedade reológica do $\mathrm{AH}$ é complexa, e as mais im- 
portantes são o módulo de viscosidade (que está relacionado com a capacidade de resistir a fase fluida das forças de cisalhamento e/ ou torção em torno de um eixo) e o módulo de elasticidade (caracteriza a firmeza do gel e mede a resistência a deformação durante a injeção). Os preenchedores dérmicos devem ser viscoelásticos que ao ser injetado sob alta pressão através de uma agulha, permaneçam elásticos para fornecer resultados duradouros e resistentes às forças de deformação de cisalhamento em tecidos moles ${ }^{22}$. Quanto mais elasticidade e viscosidade, maior a resistência às forças dinâmicas associadas aos movimentos dos músculos faciais proporcionando suporte e volumização duradouro, sendo indicado para o sulco nasolabial e linhas de marionetes ${ }^{20}$.

A coesividade do gel refere-se à capacidade para manter a forma ou a forma sob tensão, que é proporcional ao grau de atração entre as unidades de $\mathrm{AH}$ reticuladas. A coesividade aumenta com o grau de ligação cruzada (unidades dissacarídicas ligadas a uma molécula de reticulação) e a concentração de $\mathrm{AH}^{22}$.

O tamanho das partículas e a faixa de distribuição das partículas na composição dos géis de $A H$, influencia na força de extrusão necessária para a injeção. A injeção de um gel com a partícula maior é mais difícil. O AH altamente viscoelástico também afeta a capacidade de injetar o produto, por isso géis firmes com maior resistência a deformação devem ser dimensionados com partículas menores e ter uma faixa estreita de tamanho de partícula para facilitar a extrusão. Os géis com baixa viscoelasticidade podem ter uma faixa mais ampla de tamanho de partículas ${ }^{20}$. O tamanho das partículas também influencia na profundidade e degradação do produto. Produtos com partículas maiores duram mais tempo no tecido ${ }^{22}$.

\section{Uso do Ácido Hialurônico como Preenchedor e Remodelador Cutâneo}

$\mathrm{O}$ uso do $\mathrm{AH}$ se popularizou nos últimos anos por ser biocompatível e razoavelmente durável. O conhecimento detalhado da anatomia facial e o planejamento estético é de suma importância para devolver ao rosto um aspecto jovial, harmonioso e natural. Nenhum preenchedor é ideal para todas as áreas de aplicação na rotina clínica; cada preenchedor possui a profundidade cutânea que deve ser injetado ${ }^{23}$.

O nível de reticulação do $\mathrm{AH}$ e a profundidade da injeção dependem do local a ser injetado e o efeito desejado. Este efeito se estende desde o preenchimento de rugas superficiais até a remodelação de certas partes do rosto ${ }^{13}$.

Estudos têm demonstrado que existe um efeito indireto do $\mathrm{AH}$ injetado na derme, devido à ativação de fibroblastos $\mathrm{e}$ produção de colágeno. A duração dos preenchedores de $\mathrm{AH}$ em geral varia de 6 a 18 meses isso depende da concentração, reticulação e profundidade da aplicação ${ }^{1,24}$. O quadro 2 apresenta as principais vantagens o uso do $\mathrm{AH}$ em relação a outros preenchedores dérmicos.

\section{Quadro 2: Principais vantagens do preenchimento dérmico com $A H$}

\begin{tabular}{|l|}
\hline Biocompatibilidade \\
Substância absorvível \\
Baixo risco de alergia \\
\hline Não é carcinogênico \\
\hline Estimula a síntese do colágeno \\
\hline Restaura a hidratação profunda da pele \\
\hline Baixa imunogenicidade \\
\hline Muitos dados publicados sobre seu uso na prática clínica \\
\hline Procedimento quase indolor \\
\hline Resultado imediato e duradouro \\
\hline Aplicação do produto pode ser revertida através do uso da hialuronidase \\
\hline
\end{tabular}

Fonte: Monteiro 20107; Maia e Salvi 20189 ; Morais et al. $2017^{10}$.

Diversas empresas comercializam legalmente o produto, cabe ao profissional fazer escolhas personalizadas para cada paciente, com base nas propriedades químicas do $\mathrm{AH}$, na segurança, determinação adequada do volume a ser injetado, profundidade, a viscosidade, compatibilidade biológica, a forma de obtenção do produto e o custo para o paciente25.

As principais recomendações e indicações da aplicação do AH em diferentes regiões corporais durante os procedimentos estéticos são apresentadas na tabela 1.

Tabela 1. Recomendações e indicações para aplicação do AH em diferentes regiões corporais

\begin{tabular}{|c|c|c|c|c|}
\hline $\begin{array}{l}\text { Região de } \\
\text { Preenchimento }\end{array}$ & $\begin{array}{l}\text { Características } \\
\text { do } \mathrm{AH}\end{array}$ & $\begin{array}{l}\text { Classificação } \\
\text { da região }\end{array}$ & Indicações & Referências \\
\hline Frontal / Glabela & $\begin{array}{l}\text { Coesividade bai- } \\
\text { xa/moderada; e } \\
\text { moderada/ele- } \\
\text { vada resistência } \\
\text { a deformação. } \\
\text { Injetado profu- } \\
\text { damente. }\end{array}$ & $\begin{array}{l}\text { Região com } \\
\text { forças de } \\
\text { compressão } \\
\text { baixas a } \\
\text { moderadas; } \\
\text { força de } \\
\text { cisalhamento } \\
\text { moderada a } \\
\text { forte }\end{array}$ & $\begin{array}{l}\text { Linhas } \\
\text { estáticas } \\
\text { residuais; } \\
\text { Reposição } \\
\text { de volume. } \\
\text { Tratar pri- } \\
\text { meiramente } \\
\text { com neuro- } \\
\text { modulador; } \\
\text { Área mais } \\
\text { propensa a } \\
\text { necrose da } \\
\text { pele. }\end{array}$ & 26,27 \\
\hline
\end{tabular}




\begin{tabular}{|c|c|c|c|c|}
\hline Periocular & $\begin{array}{l}\text { AH tem que } \\
\text { possuir uma } \\
\text { baixa coesivi- } \\
\text { dade e baixa } \\
\text { resistência a } \\
\text { deformação. } \\
\text { Injetado } \\
\text { profundamente. }\end{array}$ & $\begin{array}{l}\text { Área com } \\
\text { pouca força } \\
\text { de compres- } \\
\text { são. }\end{array}$ & $\begin{array}{l}\text { Correção } \\
\text { de olheiras, } \\
\text { elasticidade } \\
\text { do tecido e / } \\
\text { ou ptose das } \\
\text { pálpebras. }\end{array}$ & 15,26 \\
\hline Temporal & $\begin{array}{l}\text { AH com a coe- } \\
\text { sividade forte e } \\
\text { alta resistência } \\
\text { de deformação. } \\
\text { Injeções subcu- } \\
\text { tâneas. }\end{array}$ & $\begin{array}{l}\text { Região com } \\
\text { força de } \\
\text { compressão } \\
\text { alta; força de } \\
\text { cisalhamento } \\
\text { baixa. }\end{array}$ & $\begin{array}{l}\text { Restaurar } \\
\text { a perda de } \\
\text { volume tem- } \\
\text { poral. }\end{array}$ & 15,26 \\
\hline $\begin{array}{l}\text { Terço médio da } \\
\text { face Terço mé- } \\
\text { dio da face }\end{array}$ & $\begin{array}{l}\text { AH deve possuir } \\
\text { alta coesividade; } \\
\text { moderada a ele- } \\
\text { vada resistência } \\
\text { a deformação. } \\
\text { Aplicação sub- } \\
\text { dérmica }\end{array}$ & $\begin{array}{l}\text { Região com } \\
\text { força de } \\
\text { cisalhamento } \\
\text { laterais são } \\
\text { baixas; Força } \\
\text { de compres- } \\
\text { são moderada } \\
\text { a alta. }\end{array}$ & $\begin{array}{l}\text { Restauração } \\
\text { do volume } \\
\text { malar. }\end{array}$ & 15,26 \\
\hline $\begin{array}{l}\text { Correção do } \\
\text { compartimento } \\
\text { de coxins gordu- } \\
\text { rosos. }\end{array}$ & $\begin{array}{l}\text { AH deve possuir } \\
\text { uma baixa } \\
\text { a moderada } \\
\text { resistência à } \\
\text { deformação. }\end{array}$ & $\begin{array}{l}\text { Compressão e } \\
\text { força de corte } \\
\text { nesse com- } \\
\text { partimento é } \\
\text { baixa. }\end{array}$ & $\begin{array}{l}\text { Perda dos } \\
\text { coxins gor- } \\
\text { durosos. }\end{array}$ & 15,26 \\
\hline $\begin{array}{l}\text { Nariz-Rinomo- } \\
\text { delação }\end{array}$ & $\begin{array}{l}\text { AH deve ter } \\
\text { uma baixa/ } \\
\text { moderada } \\
\text { coesividade e } \\
\text { resistência a } \\
\text { deformação. }\end{array}$ & $\begin{array}{l}\text { Força de } \\
\text { compressão } \\
\text { moderada. }\end{array}$ & $\begin{array}{l}\text { Indicado } \\
\text { para peque- } \\
\text { nas imper- } \\
\text { feições e de- } \\
\text { formidade. }\end{array}$ & 8,26 \\
\hline $\begin{array}{l}\text { Linha da } \\
\text { mandíbula }\end{array}$ & $\begin{array}{l}\text { AH deve possuir } \\
\text { coesividade e } \\
\text { resistência a de- } \\
\text { formação alta }\end{array}$ & $\begin{array}{l}\text { Zona com } \\
\text { força de } \\
\text { compressão } \\
\text { e força de } \\
\text { cisalhamento } \\
\text { moerada. }\end{array}$ & $\begin{array}{l}\text { Correção do } \\
\text { contorno da } \\
\text { mandíbula. }\end{array}$ & 15,26 \\
\hline Queixo & $\begin{array}{l}\text { AH deve ter alta } \\
\text { coesividade e } \\
\text { elevada resis- } \\
\text { tência à defor- } \\
\text { mação }\end{array}$ & $\begin{array}{l}\text { Região com } \\
\text { força de com- } \\
\text { pressão ele- } \\
\text { vada; e baixo } \\
\text { corte. }\end{array}$ & $\begin{array}{l}\text { Projeção } \\
\text { desta região. }\end{array}$ & 26,28 \\
\hline Perioral & $\begin{array}{l}\text { AH deve possuir } \\
\text { baixa/modera- } \\
\text { da coesividade; } \\
\text { Resistência ao } \\
\text { cisalhamento } \\
\text { moderada. } \\
\text { Injeção intradér- } \\
\text { mica. }\end{array}$ & $\begin{array}{l}\text { Área com bai- } \\
\text { xa compres- } \\
\text { são; força de } \\
\text { cisalhamento } \\
\text { moderada. }\end{array}$ & $\begin{array}{l}\text { Linhas finas } \\
\text { ou sulcos. }\end{array}$ & 15,26 \\
\hline Lábios & $\begin{array}{l}\text { AH com uma } \\
\text { coesividade e } \\
\text { resistência a } \\
\text { deformação } \\
\text { suave. }\end{array}$ & $\begin{array}{l}\text { Lábios ver- } \\
\text { melhos: área } \\
\text { com alta } \\
\text { compressão e } \\
\text { baixa força de } \\
\text { cisalhamento }\end{array}$ & $\begin{array}{l}\text { Restaurar } \\
\text { ou acentuar } \\
\text { as curvas } \\
\text { naturais } \\
\text { dos lábios; } \\
\text { Correção de } \\
\text { rítides. }\end{array}$ & 13,15 \\
\hline
\end{tabular}

\section{Eficácia do Uso do Ácido Hialurônico como Preenchedor} Dérmico

Atualmente os produtos preenchedores de AH são bastante seguros e moldáveis, produzindo resultados imediatos e duradouros, entretanto não permanentes. $O$ procedimento pode ser revertido com uso da hialuronidase se destacando em relação as outras substâncias preenchedoras ${ }^{9}$.

Um estudo realizado na cidade do Rio de Janeiro, Brasil, durante 32 meses, de outubro de 2012 a maio de 2015, envolvendo 280 pacientes de uma clínica dermatológica, sendo 80 do sexo feminino e 100 do sexo masculino, com idades variando de 15 a 88 anos, sendo 248 de origem caucasiana, 20 negroide e 12 oriental, foram submetidos ao preenchimento nasal, utilizando o AH da Juvederm Volift ${ }^{\oplus}$. O estudo demonstrou ser seguro e eficaz, com bons resultados estéticos rápidos, sendo alternativa à rinoplastia, apresentando poucos eventos adversos (eritema) e satisfação elevada dos pacientes. A duração dos resultados variou de paciente para paciente, mas em geral persistiram por mais de 12 meses, em alguns pacientes se manteve inalterado após 18 meses da aplicação8.

Um estudo aberto, multicêntrico, não randomizado, não controlado realizado por Talarico e colaboradores (2010)29, utilizando o AH da Perfectha ${ }^{\circledR}$ Derm, em 87 mulheres saudáveis, com idade entre 39 e 49 anos, realizou o preenchimento de sulcos nasolabiais e volume dos lábios em mulheres adultas. A avaliação da eficácia foi realizada através das escalas de melhora estética global (Global Aesthetic Improvement ScaleGAIS), e a segurança foi avaliada através dos eventos adversos. Uma semana após a aplicação houve uma melhora de $89 \%$ no aspecto da área tratada, ocorreram reações inflamatórias, transitórias, leve ou moderada e equimoses em $15 \%$ das pacientes. O AH mostrou-se seguro e eficaz, com reações imediatas previsíveis e leves.

Um estudo de revisão sistemática feito por Cohen e colaboradores30(2013), com base em cinquenta e três relatos clínicos publicados, no total de 4.605 pacientes, concluíram que o AH é um preenchedor eficaz e seguro, com usos clínicos variados, destacando-se que o total de complicações decorrentes do uso do $\mathrm{AH}$, como preenchedor facial dérmico, relatadas nestes estudos foi inferior a $1 \%$.

Outro estudo de seguimento clínico aberto, multicêntrico, prospectivo, pós-comercialização, realizado em sete locais na Alemanha e na Dinamarca, realizado com 108 pacientes, sendo 102 mulheres e 6 homens, com o objetivo de avaliar a segurança e o desempenho dos preenchedores de $\mathrm{AH}$ com lidocaína, confirmou a segurança e o desempenho do $\mathrm{AH}$, promovendo melhorias estéticas relacionadas a rítides, perda de volume facial e/ou plenitude labial. Os próprios pacientes relataram alto nível de satisfação com os resultados estéticos e baixo nível de desconforto durante os procedimentos ${ }^{31}$.

Uma revisão sistemática analisou vinte e dois estudos clínicos com AH para aumento do volume labial, e concluíram que os preenchedores dérmicos de AH são eficazes e seguros, 
ressaltando-se que a maioria dos indivíduos participantes dos estudos ficaram satisfeitos com a duração dos resultados e com sua aparência, não apresentaram reações adversas ao procedimento e nem complicações ${ }^{32}$.

\section{Contraindicações}

O produto não pode ser usado em pessoas com hipersensibilidade conhecida a estreptococos ou bactérias Grampositivas, ou em pacientes com hipersensibilidade à lidocaína para produtos que contenha o mesmo. AH composto por crista de galo é contraindicado a pacientes que tenha hipersensibilidade conhecida a proteínas de aves. Não deve ser aplicado em áreas que tenham alguma afecção cutânea, inflamações ou feridas; e em áreas com implantes permanentes. É contraindicado para mulheres grávidas e que estejam amamentando ${ }^{10}$.

\section{Recomendações para o Preenchimento Dérmico}

$\mathrm{Na}$ tentativa de amenizar ou eliminar as complicações associadas com a ponta cortante da tradicional agulha hipodérmica, foram desenvolvidas as microcânulas para injetar preenchedores. As microcânulas apresentam ponta romba e abertura lateral próximo à ponta, apresentam variações finas e flexíveis, diminuindo o trauma nos tecidos ${ }^{33}$.

Lazzeri et al.34 destacam importantes recomendações gerais para o uso preenchedores dérmicos:

- Usar a microcânula em áreas de maior chance de dano arterial, mover com suavidade para evitar laceração e estimular a vasoconstrição temporária dos vasos.

- Escolher agulhas/microcânulas de menor calibre, mesmo que a pressão inicial ao injetar o produto seja maior, favorecendo uma velocidade mais baixa de injeção, diminuindo o risco a oclusão vascular ou bloqueio do fluxo periférico.

- Aspirar antes de injetar o produto para verificar se agulha não está em uma artéria ou veia.

- Injetar pequenos volumes por vez, diminuindo o tamanho do êmbolo. Evitar a injeção de grandes volumes em planos menos distensíveis.

\section{Reações Adversas e Complicações}

No Brasil, o número de procedimentos estéticos utilizandose os preenchedores dérmicos aumentou nos últimos anos. Embora preenchimentos faciais tenham perfil de segurança muito favorável, na última década, nos Estados Unidos, a Food and Drug Administration recebeu 930 notificações de efeitos adversos pós-comercialização, 823 classificados como graves ${ }^{35}$.

As principais reações adversas causadas pelo preenchimento com AH estão são apresentadas no quadro 3.

\section{Quadro 3: Principais reações adversas da aplicação do Ácido Hialurônico}

\author{
Inflamação local \\ Hiperemia \\ Sensibilidade \\ Hematomas \\ Eritemas transitórios \\ Edema localizado \\ Efeito "Tyndall" (uma coloração azulada no local da aplicação) \\ Formação de granulomas como efeito colateral tardio
}

Fonte: Crocco et al. $2012^{14}$; Parada et al. $2016^{35}$.

As complicações vasculares são raras, e a necrose pode ser causada por oclusão ou trauma vascular; é mais propício a ocorrer na região nasolabial (artéria angular) e na glabela (supratroclear) ${ }^{35}$. Em casos de reações locais precoces após o preenchimento dérmico com AH (inflamação local, hiperemia, sensibilidade e hematomas) tem sido recomendado como tratamento a aplicação de gelo (crioterapia), fototerapia (LED e Laser de $1.064 \mathrm{~nm}$ ), o uso de anti-histamínicos e prednisona orais, por curto período de tempo. Em reações de início tardio, após o procedimento, como a formação de nódulos cutâneos tem sido descrito o uso da aplicação da enzima hialuronidase na região, a qual degrada o $\mathrm{AH}^{35,36,37}$.

As complicações também podem ser decorrentes de inexperiência do aplicador, técnica incorreta ou inerente ao próprio produto, considerando suas diferentes origens, formulações e concentrações ${ }^{14,35}$. No Brasil, os procedimentos estéticos de preenchimento dérmico facial (Harmonização Facial), normalmente, são realizados por profissionais da área da saúde especializados em procedimentos estéticos invasivos, tais como médicos dermatologistas, biomédicos, odontólogos e farmacêuticos.

\section{Conclusão}

O AH é um dos preenchedores dérmicos temporários mais usados na correção de rítides, linhas e sulcos faciais por ser seguro e eficaz. Este ácido é natural no organismo humano e dentre as suas funções destaca-se a manutenção do volume, da sustentação, da hidratação e da elasticidade da pele. Múltiplos preenchedores dérmicos estão disponíveis variando em relação às características físicas e químicas, o que influi em seus efeitos. $O$ conhecimento sobre as propriedades reológicas dos AH e suas características físico-químicas é essencial para 
escolha do produto que será aplicado em diferentes regiões para proporcionar resultados mais naturais e duradouros.

$\mathrm{O}$ AH deve ser selecionado com base na localização anatômica, características do produto para a região a ser aplicada e as necessidades individuais de cada paciente. É de suma importância o treinamento e experiência do profissional, o seu conhecimento sobre as propriedades reológicas do $\mathrm{AH}$ e a escolha adequada do produto para se obter um bom resultado, pois cada região da face é sujeita a forças mecânicas específicas. Reação inflamatória transitória, leve ou moderada e equimoses podem ocorrer alguns dias após o procedimento. Estudos revelam que bons resultados do preenchimento dérmico facial se mantêm por um período variável de 6 a 18 meses, dependendo da profundidade do preenchimento.

A maior parte dos estudos analisados demonstraram que o AH é eficaz e seguro para a correção dos sulcos, rítides e melhora do contorno e volume de diferentes regiões faciais em mulheres adultas, com reações imediatas previsíveis e leves e com possibilidade de manutenção dos resultados até 180 dias após a aplicação. O AH tem se tornado cada vez mais seguro e suas complicações na atualidade estão relacionadas principalmente à técnica de aplicação inadequada.

Avaliação cuidadosa do paciente, planejamento terapêutico adequado e técnica apurada são fundamentais para alcançar os melhores resultados com o tratamento. É de extrema importância que o profissional executor do procedimento de preenchimento esteja preparado para prontamente avaliar e lidar com possíveis efeitos adversos.

\section{Referências}

1. Coimbra DDA, Oliveira BS. Lifting supra-auricular com uso de preenchedores: nova técnica. Surgical \& Cosmetic Dermatology. 2016;8(4):328-335.

2. Fabi S, Pavicic T, Braz A, Greeen JB, Seo K, Longghem JA. Combined aesthetic interventions for prevention of facial ageing, and restoration and beautification of face and body. Clin Cosmet Investig Dermatol. 2017;10:423-429.

3. Haddad A, et al. Conceitos atuais no uso do ácido poli-l-láctico para rejuvenescimento facial: revisão e aspectos práticos. Surgical \& Cosmetic Dermatology. 2017;9(1):60-71.

4. Garbugio AF; Ferrari GF. Os benefícios do ácido hialurônico no envelhecimento facial. UNINGÁ Review. 2010;2(4):25-36.

5. Bernardes IN, Coli BA, Machado MG, et al. Preenchimento com ácido hialurônico: revisão de literatura. Saúde em Foco. 2018; 10:603-612.
6. Agostini MM, Jalil SMA. O uso do ácido hialurônico para rejuvenescimento da pele. Conexão Eletrônica - Três Lagoas, MS. 2018;15(1): 617-623.

7. Monteiro E. Envelhecimento facial: perda de volume e reposição com ácido hialurônico. Copyright Moreira Jr. Editora. 2010;67(8):299-303.

8. Coimbra DDA, Oliveira BS, Uribe NC. Preenchimento nasal com novo ácido hialurônico: série de 280 casos. Surgical \& Cosmetic Dermatology. 2015;7(4):320-326.

9. Maia IEF, Salvi JO. O uso do Ácido Hialurônico na Harmonização Facial: uma breve revisão. Brazilian Journal of Surgery and Clinical Research - BJSCR. 2018;23(2):135-139.

10. Moraes BR, Bonami JA, Romualdo L, et al. Ácido hialurônico dentro da área estética e Cosmética. Saúde em Foco. 2017; 9:552-562.

11. Garbugio AF, Ferrari GF. Os benefícios do ácido hialurônico no envelhecimento facial. Revista UNINGÁ Review, Paraná. 2010;2(4)::25-36.

12. Ferreira NR, Capobianco MP. Uso do ácido hialurônico na prevenção do envelhecimento facial. Revista Cientifica UNILAGO. 2016;1(1):1-10.

13. Bui $P$, Guiraud $P$, Lepage $C$. Apport de la volumétrie au rajeunissement facial. Partie 2: produits de comblement. Ann Chir Plast Esthet. 2017; 62(5):550-559.

14. Crocco El, Alves RO, Alessi C. Eventos adversos do ácido hialurônico injetável. Surgical \& Cosmetic Dermatology. 2012;4(3):259-263.

15. Gutowski KA. Hyaluronic Acid Fillers: Science and Clinical Uses. Clin Plastic Surg. 2016; 43(3):489-496.

16. Shamban AT, Lupo MP, et al. Comparison of smooth-gel hyaluronic acid dermal fillers with cross-linked bovine collagen: a multicenter, double-masked. Aesthet Surg J. 2015;35(5):589- 99.

17. Santoni MTS. Uso de Ácido Hialurônico Injetável na Estética Facial: Uma Revisão da Literatura. Especialização em Estética e Saúde - Universidade Regional do Noroeste do Estado do Rio Grande do Sul - UNIJUÍ, 2018.

18. Edsman K, Nord LI, Ohrlund A, Larkner H, Kenne AH. Gel properties of hyaluronic acid dermal fillers. Dermatol Surg. 2012;38(7):1170-1179.

19. Bertucci V, Lynde CB. Current Concepts in the Use of Small-Particle Hyaluronic Acid. Plastic and Reconstructive Sugery. 2015;136(5):132-138.

20. Attenello NH, Mass CS. Injectable fillers: review of material and properties. Facial Plast Surg. 2015;31(1):29-34.

21. Youn CS, Hong JY, Park KY, Kim BJ, Kim MN. A review of hydrolifting: A new modality for skin rejuvenation. 
J Cosmet Laser Therapy. 2017;20(1): 28-33.

22. Herrmann JL, Hoffmann RK, Ward CE, et al. Biochemistry, Physiology, and Tissue Interactions of Contemporary Biodegradable Injectable Dermal Fillers. Dermatol Surg. 2018;44(1):19-31.

23. Bass LS. Injectable Filler Techniques for Facial Rejuvenation, Volumization, and Augmentation. Facial Plast Surg Clin. 2015;23(4):479-488.

24. Radaelli A, Limardo P. "Minimally invasive procedures for nasal aesthetics". J Cutan Aesthet Surg. 2012;5(2):115-120.

25. Salles AG, Remigio AFN, Zacchi VBL, et al. Avaliação clínica e da espessura cutânea um ano após preenchimento de ácido hialurônico. Brass. Cir. Plást. 2011;26(1): 66-69.

26. Michaud T. Rheology of hyaluronic acid and dynamic facial rejuvenation:Topographical specificities. Wilesy Periodical, J Cosmet Dermatol. 2018;17(5):736-743.

27. Almeida ART, Sampaio GAA. Ácido hialurônico no rejuvenescimento do terço superior da face: revisão e atualização - Parte 1. Surgical \& Cosmetic Dermatology. 2016;8(2):148-153.

28. Moradi A, Watson J. Current Concepts in Filler Injection. Facial Plast Surg Clin. 2015;23(4):489-494.

29. Talarico $S$, et al. Avaliação da segurança e eficácia de novo preenchedor à base de ácido hialurônico no tratamento de sulcos nasolabiais e contorno dos lábios. Surg Cosmet Dermatol. 2010;2(2):83-86.

30. Cohen JL, et al. Systematic review of clinical trials of small冈and large冈gel囚particle hyaluronic acid injectable fillers for aesthetic soft tissue augmentation. Dermatologic Surgery. 2013;39(2):205-231.

31. Kuhne U, Esmann J, Heimburh DV, et al. Safety and performance of cohesive polydensified matrix hyaluronic acid fillers with lidocaine in the clinical setting - an open-label, multicenter study. Clin Cosmet Investig Dermatol. 2016;9:373-381.

32. Stojanovic L, Majdic N. Effectiveness and safety of hyaluronic acid fillers used to enhance overall lip fullness: a systematic review of clinical studies. Journal of Cosmetic Dermatology. 2019;1:1-8.

33. Antônio CR, Antônio JR, Coura MGG, et al. Microcânulas em dermatologia: especificações. Surgical \& Cosmetic Dermatology. 2015;7(3):241-244.

34. Lazzeri $D$, Agostini T, Figus $M$, Nardi M, Pantaloni $M$, Lazzeri S. Blindness following cosmetic injections of the face. Plast Reconstr Surg. 2012;129(4):995-1012.

35. Parada MB, Cazerta C, Afonso JPJM, Nascimento DIS.
Manejo e complicações de preenchedores dérmicos. Surg Cosmet Dermatol. 2016;8(4):342-51.

36. Winslow CP. The management of dermal filler complications. Facial Plast Surg. 2009;25(2):124-8.

37. Kim JH, Ahn DK, Jeong HS, Suh IS. Treatment algorithm of complications after filler injection: based on wound healing process. J Korean Med Sci. 2014;29 Suppl 3:S176-182. 